\title{
Travel Journey Appraisal: Communicative Evaluation Of Service Experience
}

\author{
R. J. Clarke $\mathrm{a}^{\mathrm{a}^{*}}$ \\ H. K. Brown ${ }^{\mathrm{b}}$
}

\begin{abstract}
For its users, infrastructure is not an artefact; it is in fact an experience. Understanding a customer's response to a specific transport service involves appraisal resources; communication resources by we express evaluation, attitude and emotion. Customer appraisal responses can be registered to transport systems. This literally enables maps to be created that reveal cus tomer evaluations, attitudes and emotions associated with locations along a trans port route. Comparative studies of service experience are possible by conducting appraisal analyses of interviews from different customers segments. This paper identifies the key methodological issues and their resolution to develop a communication oriented spatial normalization procedure that enables appraisal to be visualized for a journey. Using a study of authentic local shuttle services, this paper describes how the 'go along' interviews method can be conducted in order to undertake the appraisal analyses and how travel journey appraisal can be used to map customer service experience along transport routes
\end{abstract}

\section{Key words: Service experience; Communication; Systemic functional linguistics; Appraisal; mapping}

\section{Orientation to Travel Journey Appraisal Project}

While we cannot think about transport infrastructure without thinking about those who use it and ultimately pay for it, the ways we need to think about transport users' service experiences are completely different to the ways we need to think about the engineering and planning concerns associated with transport infrastructure. In attempting to understand the expectations that users have of available transport services and how they construe these experiences, traditional service marketing or service quality researchers usually employ surveys and questionnaires to quantitatively determine service satisfaction levels. While the post-hoc results of these types of quantitative studies may inform political discourse or public debate, they rarely have relevance for transport users nor can they directly inform infrastructure engineering practices. We describe part of a study called Travel Journey Appraisal (TJA) that has developed a novel approach for determining and representing transport user experiences, utilising geo-

${ }^{a}$ Collaboration Laboratory (Co-Lab), SMART Infrastructure Facility, University of Wollongong, NSW 2522

${ }^{\mathrm{b}}$ Spatial Analysis Laboratories, Faculty of Science, Medicine and Health, University of Wollongong, NSW 2522

*Corresponding author: Rodney Clarke rclarke@uow.edu.au

http://dx.doi.org/10.14453/isngi2013.proc.11 
located transcription, Systemic Functional Linguistic (SFL) communication methods for elicitation and analysis, as well as applied spatial science concepts for visualisation. While the way we recover and represent user experience is communicative and qualitative, the analysis deliverables are provided in a form that can be understood by users and directly utilised by designers, builders and maintainers of transport infrastructure. While the TJA methodology and workflow is briefly described (in $\S 2$ ), this paper emphasises the role of appraisal resources that are used to encode evaluations of service experience (in §3) and the modeling and mapping of appraisal resources (in $\$ 4$ ). These stages in the TJA methodology will be exemplified using a free city transit bus service operating in Wollongong, NSW Australia.

\section{TJA Stages, Workflow and Methodology}

The TJA methodology involves a number of stages: (A) Route Acquisition, (B) Infrastructure Modelling, (C) Interview Elicitation Practice, (D) Transcription and Standard Coding, (E) Appraisal Analysis and Coding and (F) Mapping Appraisal Resources; see Figure 1. There are three workflows that can be usefully formed from these stages. The workflow for a new complete study involves undertaking Stages A through to F inclusively; see Figure 1 (1). The Route Acquisition stage involving the collection and processing of geotraces and points of interest (Figure 1, Stage A), and the Infrastructure Modelling stage involving the construction of metric, virtual 3D infrastructure objects (Figure 1, Stage B) are not considered further here. In ongoing studies these stages would have either been completed or are not required. As a consequence, two additional workflows used for on-going studies drop the Route Acquisition stage, see Figure 1 (3.1), or drop both it and the Infrastructure Modelling stage in Figure 1 (3.2).

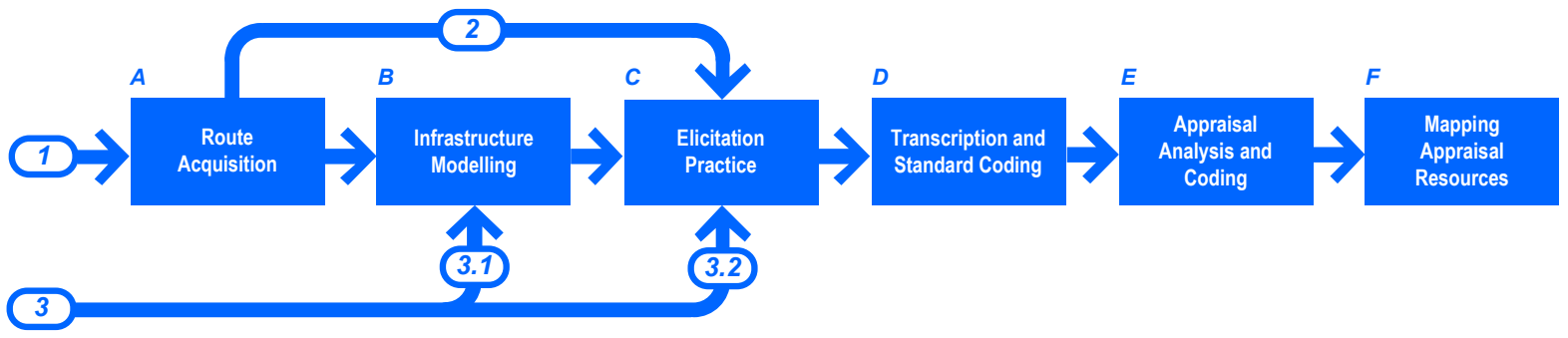

Figure 1. TJA Stages, Workflow and Methodology.

Ethnographic and ethnomethodological approaches for determining customer expectations and valuations of public transport services are not unusual ${ }^{1,2}$. Typically studies employ go-along interview techniques where the researcher and customer engage in an extended interview throughout the journey ${ }^{3}$. Go-along interviews provide transport researchers with the opportunity to study travellers' perceptions of place (locations, districts and so on) and infrastructure spaces (shelters, interchanges and the like). They also provide opportunities to observe traveller interactions with all aspects of the transport system as experienced: its physical manifestation as engineered artefacts, the functional organisation of its social groups, the signage and other informational elements that constitute soft infrastructure as well as the range of services and the manner of their provision by the transport system. In the TJA study, go-along interviews are recorded using wearable, portable digital video cameras. Their high definition removes the need for using mechanical camera stabilisation systems in the field. Undesirable camera movement can be removed as a data preparation phase. Smoothing video allows customer movements, 
gestures, and facial expressions to be clearly seen and coding if required. The wide angle lens allows views out of the bus windows and so provides a degree of locational 'ground truth' along the route. A given journey is recorded in 'one take' without edits in order to preserve the timecode. The time-code information also enables segment timings and the total journey time to be calculated and approximate location at any given time to be determined. This provides a useful backup for the small GPS unit carried by the researcher.

In traditional studies of travel experience, a think aloud protocol is often preferred as a 'naturalistic method' whereby the traveller volunteers information without any direction or prompting from the researcher ${ }^{4}$. The quality of the resulting transcript is dependent on the traveller's interest and ability to self-elicit information about the transport system during the journey. In fact using this protocol often meant that the length and quality of the transcripts was poor; travellers would simply stop talking assuming that they had nothing further to contribute ${ }^{5}$. From a communication perspective, the linguistic resources of self-elicited texts are substantially different from others. At least in travel service experience studies, the use of think-aloud protocols is not 'naturalistic'. In order to improve the duration and quality of the interactions between travellers and researchers, an elicitation practice (Figure 1, Stage C) was developed using SFLs conventional communication pattern resources (canonical genres) that we all learn as members of our respective cultures. This elicitation practice had been previously developed for use in systems development interviews ${ }^{6}$.

The go-along interview is transcribed and coded using video transcription system called Transana developed at the University of Wisconsin, forming a geocoded transcript (at Figure 1, Stage D). These transcripts can be imported into Atlas ti to provide powerful qualitative and descriptive statistical options if required. Transcripts can be coded in any number of ways. For the TJA study, the most important kind of coding involves appraisal resources (described in the next section). Stages $\mathrm{E}$ and $\mathrm{F}$ are emphasised in the remainder of the paper.

\section{Appraisal Resources}

One area that has been intensively studied in the service disciplines is the emotional content associated with services. In the services marketing literature, emotion or affect is considered to be an important aspect of the traveller's assessment of the service experience. However from a SFL perspective, affect is only one of four interrelated communication resources collectively referred to as appraisal. While it is recognised that qualitative and ethnographic approaches have the potential to access the customer's experience of transport systems and their associated services, little is understood about the language resources that stakeholders and researchers actually employ when characterising and representing experience. If we want to understand a customer's response to specific transport services then appraisal resources are particularly relevant. Appraisal resources include those communication resources by which we "express, negotiate and naturalise particular inter-subjective and ... ideological positions ... [involving] the language of evaluation, attitude and emotion"7. The earliest formulation of the Appraisal system was after Martin in educational applications ${ }^{8}$ and this formulation was subsequently adopted by Eggins and Slade in their attempts to interpret casual conversation from a systemic perspective 9 . This formulation of the Appraisal system consists of four communication resources, those associated with judging, evaluation, emotion and amplification, defined in Table 1. 
A customer who suffers from a disability like diabetes may suffer from stability issues and as a consequence may react negatively to jerky and abrupt motion in the bus (-r) while simultaneously expressing dissatisfaction (-d) and evaluating both the particular driver and their employer negatively (-s). A young mother with a stroller and a toddler may express happiness $(+\mathrm{u})$ for assistance onto a bus and judge positively the driver, their employer and those passengers who also provided aid $(+\mathrm{e})$. Various combinations of appraisal resources are possible simultaneously throughout the journey. These examples might be very useful to improve driver training or indeed identify systematic issues with the elements of the bus and the bus stop that make it difficult to manoeuvre a stroller from a path onto the bus.

Table 1. Appraisal Resources with associated probes in italics ${ }^{8,9}$. Resource codes are bracketed. Square brackets indicate lexical and/or grammatical units with $+/-$ indicating their presence/absence. Types of ranges $( \pm n$ or $0 \rightarrow n)$ for appraisal visualisation are described in the text.

\begin{tabular}{|c|c|c|}
\hline $\begin{array}{l}\text { Appreciation }(\mathrm{P}) \text { reactions to and evaluation of reality, } \mathrm{c} \\
\text { What do you think of it? }\end{array}$ & $\begin{array}{l}\text { bjects or processes } \\
\text { [lexis (adjectives), clause } \\
\text { grammar] }\end{array}$ & \\
\hline $\begin{array}{l}\text { Reaction (r) expression of emotional states both } \\
\text { positive and negative }\end{array}$ & What did/do you think of it? & $\pm \mathrm{n}$ \\
\hline $\begin{array}{l}\text { Composition (c) how harmoniousness is a social } \\
\text { process or text }\end{array}$ & $\begin{array}{l}\text { How did/does it go } \\
\text { together? }\end{array}$ & $\pm n$ \\
\hline $\begin{array}{l}\text { Valuation (v) evaluations of the content or message } \\
\text { being expressed. }\end{array}$ & How did/do you judge it? & $\pm \mathrm{n}$ \\
\hline $\begin{array}{l}\text { Affect (F) expressing feelings and emotions } \\
\text { How do you feel about it? }\end{array}$ & \multicolumn{2}{|l|}{ [lexis, + contrastive pairs $]$} \\
\hline $\begin{array}{l}\text { Un/happiness }(\mathrm{u}) \text { encoding happiness or sadness in } \\
\text { language }\end{array}$ & How happy did/do you feel? & $\pm \mathrm{n}$ \\
\hline $\begin{array}{l}\text { In/security (i) encoding anxiety or confidence in } \\
\text { language }\end{array}$ & $\begin{array}{l}\text { How secure did/do you } \\
\text { feel? }\end{array}$ & $\pm \mathrm{n}$ \\
\hline $\begin{array}{l}\text { Dis/satisfaction (d) increase or degree of intensity } \\
\text { being communicated. }\end{array}$ & $\begin{array}{l}\text { How satisfied did/do you } \\
\text { feel? }\end{array}$ & $\pm \mathrm{n}$ \\
\hline \multicolumn{3}{|c|}{$\begin{array}{l}\text { Judgement (J) evaluations of the people's ethics, morality or social values } \\
\text { How do you judge this? } \\
\text { [lexis, clause grammar] }\end{array}$} \\
\hline Social sanction (s) reactions to and evaluation of reality & $\begin{array}{l}\text { How moral? How } \\
\text { believable? }\end{array}$ & $\pm \mathrm{n}$ \\
\hline $\begin{array}{l}\text { Social esteem (e) expression of emotional states both } \\
\text { positive and negative }\end{array}$ & $\begin{array}{l}\text { How strongly committed? } \\
\text { How usual/destined? How } \\
\text { able? }\end{array}$ & $\pm \mathrm{n}$ \\
\hline \multicolumn{3}{|c|}{$\begin{array}{l}\text { Amplification (M) grading attitudes towards people, places, things or events } \\
\text { How to grade attitudes along a continuum? [lexis - contrastive pairs] }\end{array}$} \\
\hline Enrichment (n) reactions to and evaluation of reality & $\begin{array}{l}\text { Attitudinal colouring added } \\
\text { when and otherwise neutral } \\
\text { word has been used? }\end{array}$ & $0 \rightarrow \mathrm{n}$ \\
\hline $\begin{array}{l}\text { Augmenting (a) expression of emotional states both } \\
\text { positive and negative }\end{array}$ & $\begin{array}{l}\text { Amplifying or } \\
\text { intensification of attitudinal } \\
\text { meaning? }\end{array}$ & $\pm \mathrm{n}$ \\
\hline
\end{tabular}


International Symposium for Next Generation Infrastructure

October 1-4, 2013, Wollongong, Australia

\begin{tabular}{|c|c|c|}
\hline $\begin{array}{l}\text { Mitigation }(m) \text { evaluation of the ethics, morality or } \\
\text { social values of others }\end{array}$ & $\begin{array}{l}\text { Mitigate or play down } \\
\text { attitudinal meaning? }\end{array}$ & $\pm n$ \\
\hline
\end{tabular}

\section{Appraisal Modelling and Mapping}

Customer appraisal resource values can be registered to transport systems; literally enabling maps to be created that reveal customer evaluations, attitudes and emotions associated with locations along a transport route, see Figure 2. To be able to map appraisal along the transport route a number of methodological breakthroughs were required. These involved data collection and elicitation strategy described in $\$ 2$ and also how experience is encoded using Appraisal resources. One methodological problem involved determining how fine grained the spatial scale could be if communication techniques. This led to the development of communication-oriented spatial normalisation procedures that enabled appraisal to be determined at specific points along the route. Any given transport route is broken up into a number of functional segments based on the route topology, the environment along the route (the arrangement of the stops, stations, transfers stations and terminals) and the service requirements of the transport system as a whole. Segments provide a means to geo-locate appraisal resources throughout and across transport networks and provide the means to compare transport experiences between successive travelers. The user's experience is the route! Transcripts are coded for appraisal resources and the completed appraisal analysis is mapped to the segments. Each of these appraisal resources can be considered as its own intensity scale (see right hand column in Table 1 and individually visualised as shown in Figure 2. In these images, the 'ribbons' aligned to the roadways have been extruded based on ordinal intensity-based chloropleth classification. The same attribute determines the colour and the height of the ribbon at any given segment. Appraisal resources are organised using either a positive scale $(0 \rightarrow n)$ or a positive/negative scale $( \pm n)$ in Table 1. Figure 2a shows an example of the appraisal resource- enrichment (red). Those paths that provide no evidence for enrichment are presented as green.

Individual service experiences can be visualized using a GIS system as can aggregate data from multiple interviews (Figure 2a). Comparative service experience studies from different travel groups can also be visualised. Visualisations can be tailored to different stakeholders and interest groups. Figure $2 \mathrm{~b}$ shows appraisal results along one route of the free Wollongong city transit bus service as a 2D Appraisal map in ESRI ArcGIS for the iPad. Another visualisation involves a draped Appraisal extrusion over a digital elevation model in $2 \frac{1}{2} \mathrm{D}$. This would be useful for strategic decision makers and transport analysts. 


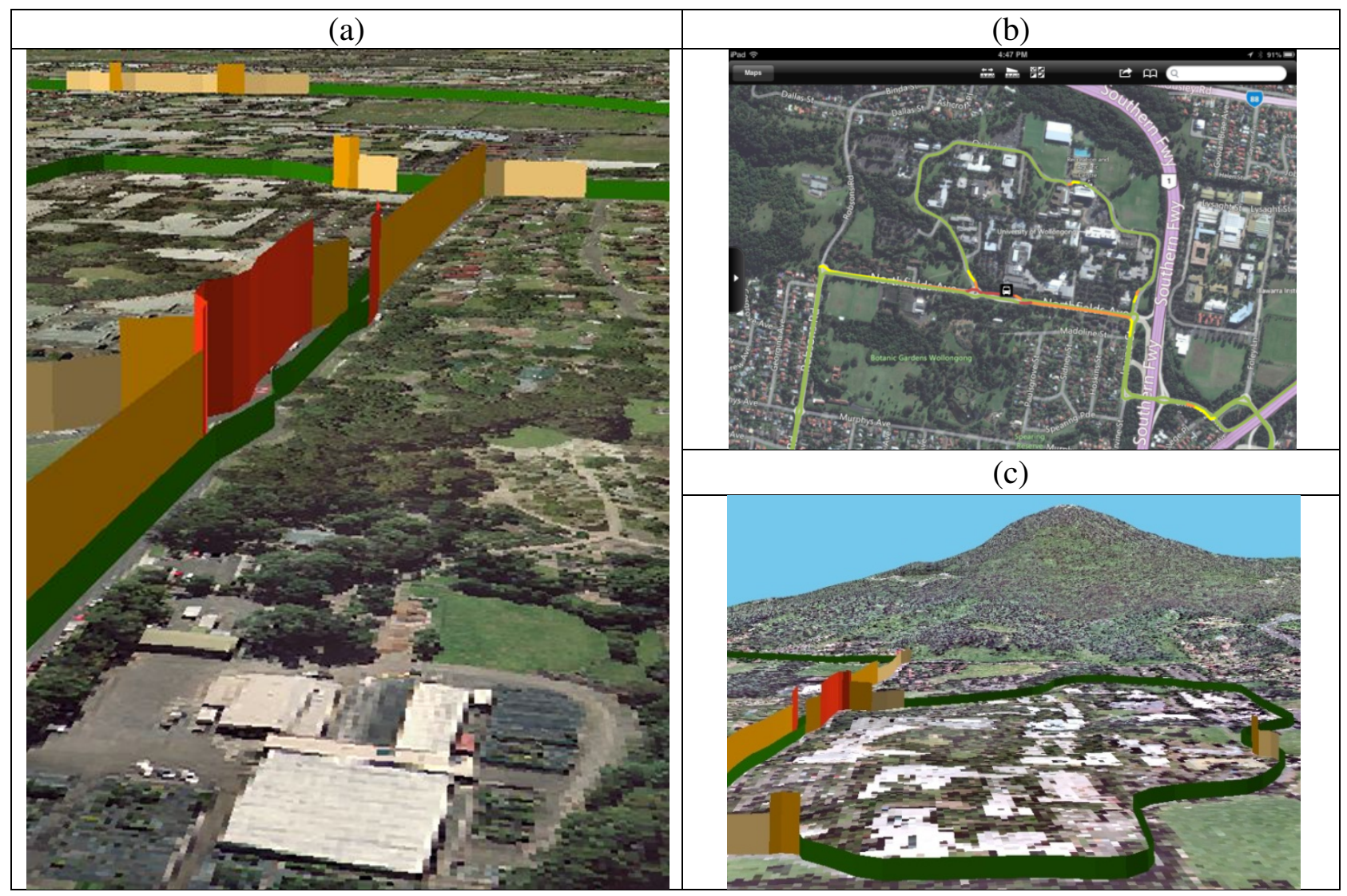

Figure 2. Mapping Appraisal Resources: (a) aggregated Enrichment from multiple journeys, (b) 2D Appraisal Map in ESRI ArcGIS for iPad, and (c) Draped Appraisal Extrusion over a Digital Elevation Model in 21/2D using ESRI ArcScene.

\section{Conclusions and Further Research}

To the best of our knowledge the geo-location and mapping of discrete user experiences of transport systems has never previously been undertaken. Perhaps this is because standard approaches to researching transport experiences had to be abandoned. The TJA study required the development of several novel communication methods, particularly the application of a theorised communication strategy to eliciting responses from travelers during go-along interviews as well as the application of appraisal methods to the resulting geo-located transcripts. A GIS was used to visualise each appraisal resource as a ribbon-like ordinal intensity-based chloropleth classification aligned to the transport route. Different visualisations suitable for travellers, transport engineers and planners are possible with this technology. The efficient application of these methods for the general public suggests a new form of Public Participation GIS (PPGIS) and more broadly a new communication-based form of travel service experience study.

With a sufficiently trained field researcher and an appropriate app, it would be possible to code appraisal resources as they occurred in real-time. This would mean it would be possible to have provisional appraisal maps developed on-the-fly as the research was being undertaken in the field without necessarily going through a lengthy transcription process. Because SFL is a comprehensive and complete model of language, the TJA methodology could be generalised to 
create many different kinds of travel communication studies. This would require the replacement of Stage E with an SFL method selection procedure. Stage F would also need to be generalised in order to visualise arbitrary combinations of communication resources.

\section{References}

${ }^{1}$ Echeverri, P., "Video-based methodology: capturing real-time perceptions of customer processes", International Journal of Service Industry Management, Vol. 16, No. 2, 2005, pp. 199-209. http://dx.doi.org/10.1108/09564230510592315

${ }^{2}$ Salmonson, N., "Conversation Analysis and Service Encounters: An Ethnomethodological Approach when Studying Voice-to-Voice Encounters", in Ford, R. C.; Dickson, D. R.; Edvardsson, B.; Brown, S. W. and Johnston, R. (Editors), Managing Magical Service, Proceedings of The 10th International Research Symposium on Service Excellence in Management, Orlando, Florida, 2007, pp. 316-325.

${ }^{3}$ Jones, P., Bunce, G., Evans, J., Gibbs, H., and Ricketts Hein, J., "Exploring space and place with walking interviews", Journal of Research Practice, Vol. 4, No. 2, Article D2, 2008, URL: http://jrp.icaap.org/index.php/jrp/article/view/150/161

${ }^{4}$ Olmsted-Hawala, E., Murphy, E., Hawala, S., and Ashenfelter, K., "Think-Aloud Protocols: A Comparison of Three Think-Aloud Protocols for use in Testing Data Dissemination Web Sites for Usability", Proceedings of CHI 2010, ACM Conference on Human Factors in Computing Systems, ACM Press, 2010, pp. 2381-2390.

${ }^{5}$ Clarke, R. J., Semantic Aspects of Travel Servicescapes: Interim Report Contract Research, Services and Market Oriented Transport Research Center (SAMOT), Karlstad University, Sweden, 2009.

${ }^{6}$ Clarke, R. J., "The Work that Analysts Do: A Systemic Functional Approach to Elicitation", Advances in Information Systems Development: Proceedings of the 14th International Conference on Information Systems- Development Bridging the Gap between Academia and Industry, Vol. 1, NY: Springer Science + Business Media, 2006, pp. 325-336.

${ }^{7}$ White, P.R.R., The Appraisal Website: Language of Attitude, Arguability and Interpersonal Positioning, 2011, URL: http://www.grammatics.com/appraisal/index.html

${ }^{8}$ Martin, J. R., English Text. System and Structure, John Benjamins, Philadelphia/Amsterdam, 1994.

${ }^{9}$ Eggins, S., and Slade, D., Analysing Casual Conversation, Cassel, London, UK, 1997, pp. 124143. 